\title{
Commentary: Dysregulated Microbial Fermentation of Soluble Fiber Induces Cholestatic Liver Cancer
}

\author{
Baolei Jia*, Ruiming Wang, Jie Zhang and Yuxia Chi \\ State Key Laboratory of Biobased Material and Green Papermaking, School of Bioengineering, Qilu University of Technology \\ (Shandong Academy of Sciences), Jinan, China
}

Keywords: gut microbiome, soluble fiber, liver cancer, bile acids, immune regulation

\section{A Commentary on}

\section{OPEN ACCESS}

Edited by:

Moez Rhimi,

INRA Centre Jouy-en-Josas, France

Reviewed by:

Bjoern O. Schroeder,

Umeå University, Sweden

Nagendra Singh,

Augusta University, United States

Leigh Greathouse,

Baylor University, United States

*Correspondence:

Baolei Jia

baoleijia@cau.ac.kr

Specialty section:

This article was submitted to Microbiome in Health and Disease,

a section of the journal

Frontiers in Cellular and Infection

Microbiology

Received: 19 January 2019 Accepted: 26 April 2019

Published: 21 May 2019

Citation:

Jia B, Wang $R$, Zhang J and Chi Y (2019) Commentary: Dysregulated

Microbial Fermentation of Soluble

Fiber Induces Cholestatic Liver

Cancer.

Front. Cell. Infect. Microbiol. 9:155.

doi: 10.3389/fcimb.2019.00155
Dysregulated Microbial Fermentation of Soluble Fiber Induces Cholestatic Liver Cancer by Singh, V., Yeoh, B. S., Chassaing, B., Xiao, X., Saha, P., Aguilera Olvera, R., et al. (2018). Cell 175, 679-694.e622. doi: 10.1016/j.cell.2018.09.004

In this article, Singh et al. have shown that feeding innate immune-deficient mice a diet enriched in soluble fibers (including inulin, pectin, and fructo-oligosaccharides) but not insoluble fibers could induce liver cancer (Figure 1) (Singh et al., 2018). Fiber-induced liver cancer did not occur in WT mice, however, WT mice fed a high-fat diet (HFD) could be susceptible to liver cancer upon consumption of soluble fibers. These induced cancers are initiated with cholestasis, followed by hepatocyte death and neutrophilic inflammation in the liver. Liver cancer is influenced by diet and dependent on microbiota; a previous dysbiosis should be required for carcinoma development. The mice model that developed liver cancer in this study displayed a dysbiosis characterized by accumulation of fiber-fermenting bacteria and proteobacteria. Cohousing or cross-fostering of dysbiotic mice with WT mice indicated that liver cancer is transmissible, which further verified a causative role of microbiota in fiber-induced liver cancer.

Soluble fibers that can be fermented by gut microbiota include inulin, resistant starch, resistant maltodextrins, soluble corn fiber, and polydextrose. Such soluble fibers are recognized as prebiotics because they can be fermented to short-chain fatty acids (SCFAs), which are important for human health (Holscher, 2017). High inulin intake (20\%) has been shown to reduce microbiota encroachment, restore lost enterocyte proliferation due to HFD, and improve gut health in mice (Zou et al., 2018). The authors of the current article initially tested whether inulin could alleviate metabolic syndrome in TLR5 knockout (T5KO) mice, by feeding the mice an inulin-containing diet (ICD). They observed that the sera of $\sim 40 \%$ of mice without metabolic syndrome showed a yellow color, caused by elevated bilirubin levels during the experiments. Finally, based on their observations, the authors concluded that refined fermentable fibers can induce cholestasis followed by liver cancer in mice (Singh et al., 2018). Another study showed that inulin-type fructans have anti-tumorigenic effects in colon cancer (Pool-Zobel, 2007). The contrasting conclusion of the current study extends our knowledge of the effects of various types of dietary fiber on health. The findings support the idea that whether soluble fibers and their fermentation products are beneficial is highly dependent on internal and 


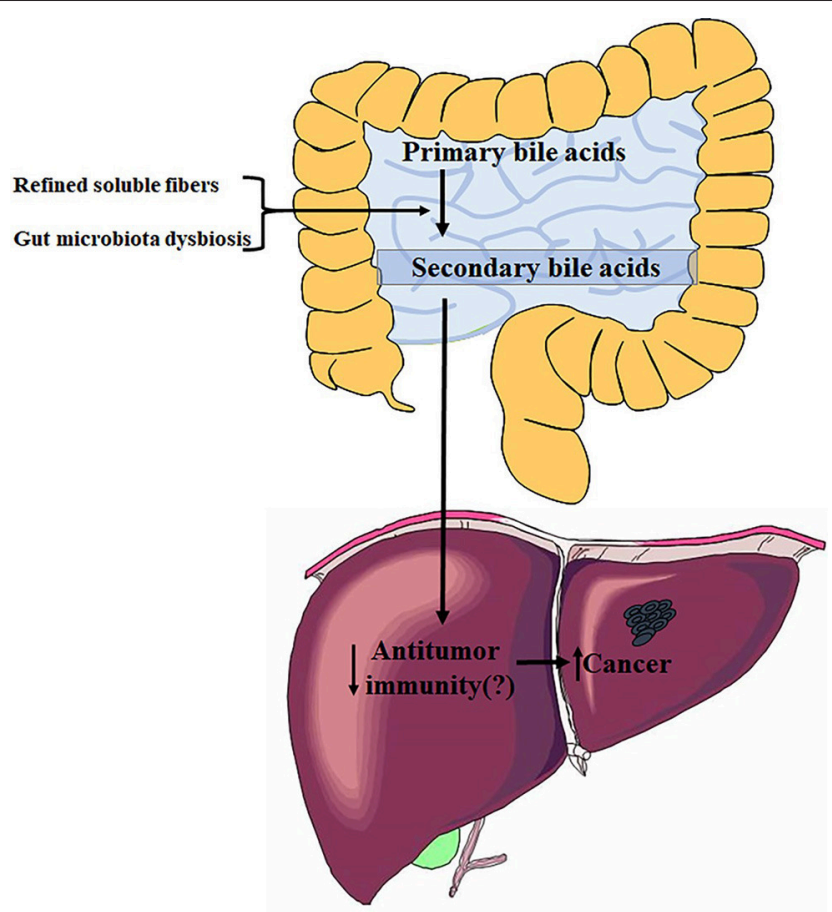

FIGURE 1 | Influence of refined soluble fibers on gut microbiota dysbiosis and liver health. The figure summarizes data from Singh et al. (2018).

environmental conditions (Perry et al., 2016). The study also indicated that enrichment of foods with dietary fibers to provide health benefits should be practiced with great caution.

\section{REFERENCES}

Holscher, H. D. (2017). Dietary fiber and prebiotics and the gastrointestinal microbiota. Gut microbes 8, 172-184. doi: 10.1080/19490976.2017.1290756

Loo, T. M., Kamachi, F., Watanabe, Y., Yoshimoto, S., Kanda, H., Arai, Y., et al. (2017). Gut Microbiota promotes obesity-associated liver cancer through PGE2-mediated suppression of antitumor immunity. Cancer Discov. 7, 522538. doi: 10.1158/2159-8290.cd-16-0932

Ma, C., Han, M., Heinrich, B., Fu, Q., Zhang, Q., Sandhu, M., et al. (2018). Gut microbiome-mediated bile acid metabolism regulates liver cancer via NKT cells. Science 360:eaan5931. doi: 10.1126/science.aan5931

Perry, R. J., Peng, L., Barry, N. A., Cline, G. W., Zhang, D., Cardone, R. L., et al. (2016). Acetate mediates a microbiome-brain- $\beta$-cell axis to promote metabolic syndrome. Nature 534, 213-217. doi: 10.1038/nature18309

Pool-Zobel, B. L. (2007). Inulin-type fructans and reduction in colon cancer risk: review of experimental and human data. Br. J. Nutr. 93, S73-S90. doi: 10.1079/BJN20041349

Ridlon, J. M., Kang, D. J., Hylemon, P. B., and Bajaj, J. S. (2014). Bile acids and the gut microbiome. Curr. Opin. Gastroenterol. 30, 332-338. doi: 10.1097/mog.0000000000000057

Singh, V., Yeoh, B. S., Chassaing, B., Xiao, X., Saha, P., Aguilera Olvera, R., et al. (2018). Dysregulated microbial fermentation of soluble fiber
The authors of this study showed that Clostridia species are enriched in the guts of mice with live cancer, including the Clostridium cluster XIVa, which performs a key enzymatic transformation of primary to secondary bile acids in the gut (Ridlon et al., 2014). Previous studies have indicated that Clostridium cluster XIVa and the secondary bile acids produced by them play important roles in promoting obesity-associated liver cancer (Figure 1). The accumulation of secondary bile acids in the livers of HFD mice suppresses anti-tumor immunity through a PTGER4 receptor on CD8 cells, which is mediated by the Toll-like receptor 2 (TLR2) signaling pathway, thereby contributing to liver cancer progression (Yoshimoto et al., 2013; Loo et al., 2017). Bile acids can also function as messengers to regulate liver cancer by controlling the accumulation of hepatic natural killer $\mathrm{T}$ (NKT) cells in a chemokine-dependent manner (Ma et al., 2018). The current research advances these studies by showing that gut microbiota can induce liver cancer in inulin-fed T5KO mice, and that oncogenic bacteria are transmissible to susceptible mice, as demonstrated by co-housing or cross-fostering. The article did not identify specific oncogenic bacteria. Overall, these studies on relationships between gut microbiota and liver cancer suggest that Clostridium cluster XIVa, Clostridium cluster XI, or other strains catalyzing the transformation from primary to secondary bile acids could be promoters of liver oncogenesis.

\section{AUTHOR CONTRIBUTIONS}

BJ wrote the commentary. RW, JZ, and YC helped to write.

induces cholestatic liver cancer. Cell 175, 679-694. doi: 10.1016/j.cell.2018. 09.004

Yoshimoto, S., Loo, T. M., Atarashi, K., Kanda, H., Sato, S., Oyadomari, S., et al. (2013). Obesity-induced gut microbial metabolite promotes liver cancer through senescence secretome. Nature 499, 97-101. doi: 10.1038/nature 12347

Zou, J., Chassaing, B., Singh, V., Pellizzon, M., Ricci, M., Fythe, M. D., et al. (2018). Fiber-mediated nourishment of gut microbiota protects against dietinduced obesity by restoring IL-22-mediated colonic health. Cell Host Microbe 23, 41-53. doi: 10.1016/j.chom.2017.11.003

Conflict of Interest Statement: The authors declare that the research was conducted in the absence of any commercial or financial relationships that could be construed as a potential conflict of interest.

Copyright (c) 2019 Jia, Wang, Zhang and Chi. This is an open-access article distributed under the terms of the Creative Commons Attribution License (CC BY). The use, distribution or reproduction in other forums is permitted, provided the original author(s) and the copyright owner(s) are credited and that the original publication in this journal is cited, in accordance with accepted academic practice. No use, distribution or reproduction is permitted which does not comply with these terms. 